\title{
Yatay Kuyruklarda Kıvrık Kanat Ucu Kullanımının Aerodinamik Etkileri Öztürk Özdemir Kanat ${ }^{1 *}$, Durmuş Sinan Körpe ${ }^{2}$, Ali Osman Kurban ${ }^{3}$ \\ ${ }^{1}$ Uçak Gövde-Motor Bölümü, Sivil Havacılık Yüksekokulu, Kastamonu Üniversitesi ${ }^{2}$ Uçak Mühendisliği Bölümü, Havacılık ve Uzay Bilimleri Fakültesi, Türk Hava Kurumu Üniversitesi \\ ${ }^{3}$ Uçak Gövde-Motor Bölümü, Havacılık ve Uzay Bilimleri Fakültesi, Erciyes Üniversitesi
}

\section{Özet}

Bu çalışmada, NACA 0012 simetrik kanat profiline sahip, ticari amaçlı bir yolcu uçağının yatay dengeleyicisi ve bu yatay dengeleyicinin ucuna yerleştirilen iki farklı kıvrık kanat ucu yapısının üzerinde farklı hücum açılarında oluşan aerodinamik kuvvetler incelenmiştir. Yatay dengeleyici, SolidWorks tasarım programında 200 noktadan oluşan kanat profili eğrisi ve belirlenen $\mathrm{V}$ açısı, ok açısı ve sivrilme oranları kullanılarak tasarlanmıştır. $\mathrm{Bu}$ tasarım $\mathrm{C}_{1}$ olarak tanımlanmıştır. $\mathrm{C}_{1}$ tasarımının uç kısmına, aynı ok açısına, bükme açısına, sivrilme oranına, açıklığa, yüksekliğe sahip; fakat uç kısmındaki kanat profili kalınlığı farklı olan iki kıvrık kanat ucu yapısı tasarlanarak toplamda üç kanat tasarımı elde edilmiştir. $\mathrm{Bu}$ tasarımlar sırası ile $\mathrm{C}_{2}$ ve $\mathrm{C}_{3}$ olarak adlandırılmıştır. Üç farklı tasarımın aerodinamik analizi, bir hesaplamalı akışkanlar dinamiği programı olan Fluent kullanılarak yapılmıştır. On üç farklı hücum açısında gerçekleştirilen analizler sonucunda elde edilen sonuçlara göre tasarımların üzerindeki sürükleme $\left(C_{D}\right)$ ve taşıma $\left(C_{L}\right)$ katsayılarındaki değişimler gözlemlenmiştir. Elde edilen sonuçlara göre, $\mathrm{C}_{2}$ tasarımı için analizlerin yapıldığı bütün hücum açılarında daha yüksek taşıma kuvvetinin sürükleme kuvvetine oranına $\left(C_{L} / C_{D}\right)$ sahip olduğu görülmüştür. $C_{3}$ tasarımı için ise -1 derece hücum açısındaki sonuç haricinde aynı sonuç elde edilmiştir.

Anahtar Kelimeler: Yatay Dengeleyici, Kıvrık Kanat Ucu, NACA 0012, HAD

\section{The Aerodynamic Effects of The Using Curved Wingtip Devices on Horizontal Tail}

\begin{abstract}
In this study, aerodynamic forces on a horizontal stabilizer of commercial aircraft that has NACA 0012 airfoil and new horizontal stabilizers that are designed by mounting two different curved wingtip devices (winglet) to the preliminary horizontal stabilizer at different angle of attack values. The preliminary horizontal stabilizer is designed by the airfoil shape that is composed of 200 points and determined span, root chord, dihedral angle, sweep angle and taper ratio values. This design is defined as $\mathrm{C}_{1}$. Two curved wingtip devices that have the same sweep angle, cant angle, taper ratio, span and height but different airfoil thickness ratio at tip are designed and mounted to the $\mathrm{C}_{1}$. These are named as $\mathrm{C}_{2}$ and $\mathrm{C}_{3}$, respectively. The aerodynamic analyses of these designs are done by using Fluent that is a well-known computational fluid dynamics program. The analyses are performed at 13 different angle of attack values and the alterations on drag $\left(C_{D}\right)$ and lift $\left(C_{L}\right)$ coefficients of the designed horizontal tails are observed. According to the results, $C_{2}$ has higher lift to drag ratio $\left(C_{L} / C_{D}\right)$ values at all angle of attack values. For the $C_{3}$ design, the same result has been seen except for the result of -1 degree angle of attack.
\end{abstract}

Keywords: Horizontal Stabilizer, Curved Wingtip Devices (Winglet), NACA 0012, CFD

\footnotetext{
*Sorumlu Yazar: ozturkkanat@gmail.com
} 


\section{Giriș}

Dünyadaki buluşların ve teknolojik gelişmelerin ilk uygulama alanı olan havacılık sektörünün en hızlı büyüyen sektörlerden biri olmasının başlıca sebebi taşımacılıktır. Hava taşımacılığ 1 denildiğinde sadece yolcu taşımacılığı akla gelmeyip, kargo ve askeri taşımacılık işlemleri de düşünülmelidir. Hava taşımacılığının dünya ekonomisindeki yeri her geçen gün giderek artmaktadır. Uluslararası Hava Taşımacıllı̆ Association-IATA) verilerine göre 2015 y1lında hava taşımacılığ $1 \% 2,3$ uzun vadede ücretli yolcu sayısındaki artış ortalama \% 5,5 olarak tahmin edilirken 2015 y1lı sonunda ücretli yolcu sayısındaki artış \% 7,4 olarak meydana gelmiştir. Gelecek yirmi yıl için yapılan tahminler için hava taşımacılığına olan talebin katlanarak artacağ 1 öngörülmektedir [1]. Havacılık sektörüne artan talep nedeniyle yeni şirketler kurulmakta ve uçak sayıs1 giderek artmaktadır. $\mathrm{Bu}$ durum daha da rekabete dayalı ortam oluşturmaktadır. Üretici ve işletmeci firmaların bu zorlu rekabet ortamında birbirleriyle mücadele edebilmeleri için her geçen gün teknolojik yenilikleri takip etmeleri gerekmektedir. Uçak üreticisi bir firma tarafindan üretilen uçağın işletmeci firmalar tarafından satın alınıp kullanılabilmesi için öncelikle ihtiyaçları en az masrafla karşılayan bir model olması gerekmektedir. Kısacası bir uçak modelinin işletme maliyetleri ve güvenilirliği en önemli faktörlerdir. İşletme maliyetini oluşturan parametreler arasında uçağın yakıt sarfiyat değerleri en başlarda gösterilebilmektedir. Gerçekte bir uçağın üretilip test uçunda incelenmesi çok maliyetli ve uzun zaman alan bir süreçtir. $\mathrm{Bu}$ sebepten dolayı uçakların küçük modelleri yapılarak uçağın gerçekte maruz kalacağı ortam şartlarının oluşturulabildiği rüzgar tünellerinde deneysel incelemesi yapılmaktadır. Buna ek olarak, son yıllarda gelişen bilgisayar teknolojisi sayesinde akış çözücü programlar kullanılarak deneysel sonuçlara oldukça yakın olan sayısal veriler elde edilebilmektedir. Uçaklarda yakıt sarfiyatının azaltılabilmesi için uçak üzerinde meydana gelen sürükleme kuvvetinin en düşük hale getirilmesi gerekmektedir. Sürükleme kuvvetinin sıfır olması mümkün değildir; fakat uçuşun tüm evrelerinde en düşük seviyede tutulacak şekilde tasarım yapılabilmesi halinde yakıt sarfiyatı azaltılabilecektir. Bunun için üretici firmalar uçaklar üzerinde üretim esnasında ya da sonradan aerodinamik iyileştirmeler gerçekleştirmektedirler. $\mathrm{Bu}$ durum için en uygun örnek bazı uçak modellerinin kanatlarına sonradan kıvrık kanat ucu yapılarının eklenmesidir. Böylelikle kanat uç kısımlarında taşıma kuvveti artarken, kanat alt ve üst kısmından akan havanın kanat uç kısımlarında karşılaşarak aralarındaki basınç farkı nedeniyle meydana getirdikleri girdaplar sonucu oluşan indüklenmiş sürükleme kuvvetinde azalma tespit edilmiştir. Kanat yapısına bağlı olarak çeşitli kıvrık kanat ucu yapıları en iyileme süreci ile tasarlanarak sayisal ve deneysel incelemeler sonucunda uçaklarda kullanılmaya başlanmıştır. Günümüzde kıvrık kanat ucu yapıları indüklenmiş sürüklemede azalma meydan getirmelerinden dolayı, uçaklarda ana taşıyıcı görevini gören kanatlarda kullanılmaktadır. Bu çalışmada ise ilk defa bir yolcu uçağının yatay dengeleyicisi olabilecek ölçütlerdeki bir kanat için kıvrık kanat ucu tasarlanmış ve aerodinamik etkileri incelenmiştir.

Maughmer [2], yüksek performanslı bir planör için kıvrık kanat ucu tasarlamıştır. Bir planöre göre kıvrık kanat ucu tasarımı için başlangıçta sınırlı parametreler biliniyor olmasına rağmen, planör performansını artıran kıvrık kanat ucu tasarımı için kolay metotlar kullanmıştır. Elde ettiği bu kazanımlar genel anlamda kıvrık kanat ucu tasarımları için de yöntem oluşturmuştur. Maughmer ve arkadaşları [3], tarafindan bir planör için PSU 94-097 profilini kullanarak kıvrık kanat ucu yapısı tasarlanmış ve test edilmiştir. Tasarlanan kanadı düşük hızlı ve düşük türbülanslı rüzgar tünelinde farklı Reynold sayılarında test edilmiştir. Aynı zamanda taşıma katsayısının farklı uçuş evrelerindeki değişimi iki kanat tasarımı için de karşılaştırmalı grafiksel olarak sunulmuştur. Deneysel olarak elde edilen sonuçları bilinen iki bilgisayar kodu ile karşılaştırılmış ve sonuçların uyuştuğu görülmüştür. Menter ve arkadaşları [4] tarafından dış akış çözümleri için kullanılabilen bir türbülans modeli olan SST türbülans modelinin gelişimine yönelik incelemeler yapılmıştır. $\mathrm{Bu}$ incelemelere göre duvar üzerindeki akışın meydana getirmiş olduğu değişimler grid duyarlılığına daha 
az hassasiyet oluşturacak şekilde formüle edilmiştir. Kıvrık kanat ucu yapıları, kanat uç kısmında yer alan dikey eksende uzantıya sahip olan ve uçağın yakıt sarfiyatını azaltarak düz uçuş performansına olumlu katkı sağlaması amacıyla tasarlanan küçük kanatlardır. Uçağın hava içinde yüzmesi sonucunda kanat uçlarındaki girdaplar nedeniyle oluşan aerodinamik sürüklemeleri en aza indirgemek amacıyla tasarlanmışlardır. Sürüklemenin azalmasının sonucunda yakıt sarfiyatı düşmekte ve uçağın menzili uzamaktadır. Nicolosi ve arkadaşları [5], yapmış oldukları çalışmada kıvrık kanat ucu tasarlanan küçük gövdeli çift motorlu bir uçak için yapılan analizler sonucunda kalkış ve iniş mesafesinin kısaldığ 1 ve dolayısıyla yer performansında önemli derecede artış olduğu gözlemlenmiştir. En küçük uçaktan en büyüğüne kadar hepsi kıvrık kanat ucu yapısıyla uçuşunu gerçekleştirebilmektedir. Günümüzde yolcu taşımacılığı için kullanılan bazı uçak modellerine üreticinin önerisi ile işletmeci firmalar olumlu katkılarından dolayı uçaklarına sonradan kıvrık kanat ucu yapısı taktırmışlardır [6]. 1970' lerin ilk yıllarında Dr. Richard Whitcomb uçak yakıt fiyatlarındaki artış nedeniyle ortaya çıkan yakıt sarfiyatının azaltılması gerekliliğinin kıvrık kanat ucu yapılarıyla sağlanabileceğini düşünerek tekrar bu konu üzerine çalışmalar yapmıştır. Whitcomb NASA' da havacılık mühendisi olarak çalışmış, kıvrık kanat ucu yapılarıyla ilgili hem rüzgar tüneli deneyleri hem de bilgisayar çalışmaları yürütmüştür. Whitcomb tarafindan yapılmış olan bazı araştırmalara göre uçaklarda kıvrık kanat ucu tasarımının verimliliği \% 6 ila \% 9 arasında artırdığ belirlenmiştir [7]. Elham ve Tooren [8] tarafından var olan bir uçak tasarımına winglet eklenmesi için optimizasyon tekniklerinin kullanımıyla ilgili bir çalışma yapılmıştır. Orta ve uzun menzilli yolcu uçakları için optimizasyon yöntemleri kullanılmıştır. Kanat dış şeklinde değişiklik yapılmamış; fakat uç kısımda farklı gerilme ve ağırlık yüklemeleri olacağı için kanat içinde yapıyla ilgili kısımlarda değişiklikler yapılmıştır. Optimizasyon sonucuna göre winglet kullanımıyla sürüklemede azalma belirlenmesine rağmen, yakıt tasarrufu olduğunun daha çok uzun mesafe uçakları olan geniş gövde uçak modelleri için düşünülebileceğini belirtmişlerdir. Bunun temel sebebinin yakıt ağırlığıyla kanat ağırlığ farklılığın olduğu söylenmiştir. $\mathrm{Bu}$ çalışma sonucunda, dar gövde kısa mesafeli uçaklar için bu oranın birbirine yakın olması nedeniyle yakıt tasarrufunun geniş gövde uçaklar kadar olamayacağı ortaya konulmuştur.

\section{Materyal ve Yöntem}

$\mathrm{Bu}$ çalışmada, yatay dengeleyici açıklığının fazla olduğu geniş gövdeli bir yolcu uçağının yatay dengeleyicisini oluşturabilecek değerlerde bir kanat tasarlanmış ve bu tasarımın uç kısımlarına kıvrık kanat ucu yapıları eklenerek karşılaştırmalı olarak farklı hücum açılarında sayısal incelemesi yapılmıştır. Sayısal incelemeyle amaçlanan kıvrık kanat ucu tasarımlarının yalın tasarıma göre taşıma ve sürükleme kuvvetlerinde meydana getirmiş oldukları değişimlerin karşılaştırılmasıdır. Dolayısıyla taşıma kuvvetinin artırılıp; sürükleme kuvvetinin azaltılarak uçuş performansının olumlu etkilenmesi amaçlanmıştır. Uçak kuyruk takımı profil yapıları farklı kamburlukta yapılara sahip olabildikleri gibi simetrik yapıya da sahip olabilmeleri nedeniyle kanat profil yapısı olarak, simetrik bir yapıya sahip olan NACA 0012 profili kullanılmıştır. Kıvrık kanat profil yapısı olarak aynı profil kullanılmış ve iki farklı kalınlıkta uç kısmına sahip kıvrık kanat ucu tasarımı oluşturulmuştur. Elde edilen bu üç farklı tasarımın, geniş gövdeli bir uçağın düz uçuşunu gerçekleştirdiği irtifadaki ortam şartları belirlenmiş ve sayısal incelemeleri bu değerlere göre yapılmıştır. Kıvrık kanat ucu yapısına sahip olmayan normal kanat profili ve diğer iki tasarım için de uygulanan analizler sonucunda elde edilen taşıma ve sürükleme kuvvetleri hesaplanmıştır. 
Tablo 1. Normal kanat tasarımı için kullanılan değerler

\begin{tabular}{cc}
\hline Parametre İsmi & Sayısal Değerler \\
\hline V açısı & 6,5 derece \\
Ok açısı & 33 derece \\
Sivrilme oranı & 0,35 \\
Kök veter uzunluğu & 7 metre \\
Açıklık oranı & 4,25 \\
Kanat açıklı̆̆ı & 10 metre \\
\hline
\end{tabular}

Kanat tasarımı için kullanılan NACA 0012 kanat profilinin koordinatları iki yüz noktadan oluşacak şekilde tanımlanmıştır. Tanımlanmış olan bu koordinatlar bir çizim programı olan SolidWorks'e aktarılarak uzunluğu 7 metre olan kök veter oluşturulmuştur. Yatay stabilizatör diğer tasarım parametreleri Tablo 1'de gösterilmiştir.

Şekil 1 ve Şekil 2'de tasarlanan yarım yatay dengeleyicinin yandan ve önden görünüşleri gösterilmektedir.

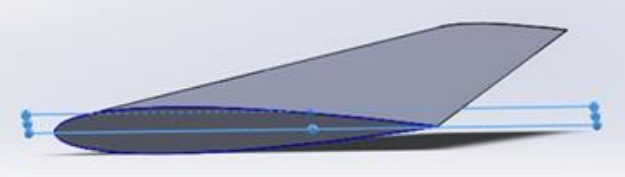

Şekil 1. $C_{1}$ konfigürasyonu sivrilme oranı ve ok açıs1

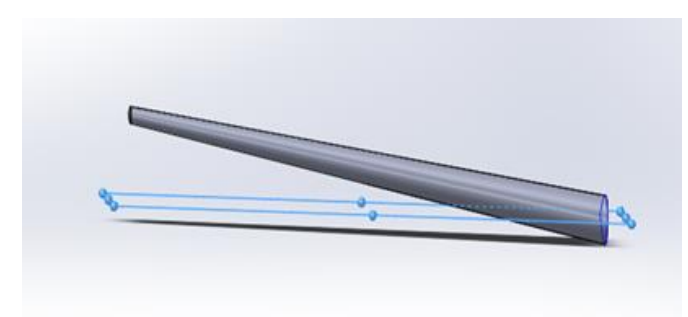

Şekil 2. $\mathrm{C}_{1}$ konfigürasyonu $\mathrm{V}$ açısı

Kıvrık kanat ucu tasarımlarına sahip olan $\mathrm{C}_{2}$ ve $\mathrm{C}_{3}$ konfigürasyonları $\mathrm{C}_{1}$ konfigürasyonunun uç kısmından başlanarak tasarlanmıştır. Kıvrık kanat ucu tasarımında bazı tanımlamalar kullanılmakta ve tasarım bu tanımlamalara göre yapılmaktadır.
Kıvrık kanat ucu tasarımı yapılırken çift taraflı (altlı ve üstlü) olarak yapılmasına karar verilmiştir. Sürükleme kuvvetindeki azalış standart kıvrık kanat ucu tasarımına göre çift taraflı tasarımda daha fazla olduğu daha önce yapılan bir çalışma ile ortaya konulmuştur [9]. Araştırmacılar bu çalışmada, çift taraflı tasarımın standart kıvrık kanat ucu tasarımına göre \% 2 ya da daha az sürükleme meydana getirebilmesi için alt yüzeyle üst yüzey arasında yükseklik oranı olarak en uygun değerin 0,4 kat olduğunu belirtmişlerdir. Tasarım esnasında bu oran göz önünde bulundurulduğunda uçakların düz uçuş yüksekliğine en kısa zamanda tırmanabildiği ve çıkarmış oldukları gürültüde azalma görülmüştür. Bunun yanında uçağın kontrol edilebilirliğine ve kumandalara cevap verme süresinde herhangi bir olumsuz etkisi görülmemiştir [10].
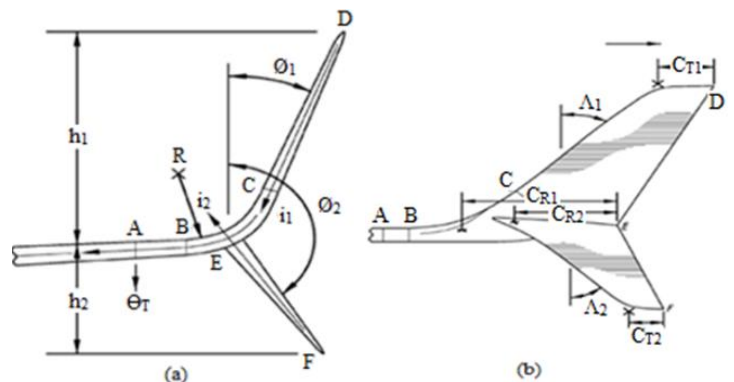

Şekil 3. Referans alınan kıvrık kanat ucu tasarımı [10]

Şekil 3'te görüldüğü gibi, üst kısım kök veter uzunluğu kanat uç veter uzunluğu ile aynıkken, alt yüzey kök kısmı veter uzunluğu her ikisinin veter uzunluğundan kısadır. Geçiş bölgesi (B-C) oluşturulurken bir eğrinin yarıçapı kullanılmıştır. $\mathrm{Bu}$ yarıçap değişkenlik gösterebilmektedir. Uç kısım (C-D) ise bu eğriye düzlemsel olarak bağlanmaktadır. Alt yüzey geçiş bölgesine dik açılı olacak şekilde oluşturulmuştur. $\mathrm{Bu}$ şekilde oluşturulurken kanat eğilme momenti düşünülmüştür. $\mathrm{R}$ yarıçapı geçiş bölgesindeki veter uzunluğu değişimlerine uyumluluk gerektirmektedir. $R$ hesaplanırken, $K_{R}$ eğrilik kriteri göz önünde bulundurularak bazı parametrelerden yararlanılmıştır. $K_{R}$ değeri 0,35 ile 0,50 aralı̆̆ında olacak şekilde kabul edilmiştir. Diğer bir göz önünde bulundurulan parametre ise cant (Ø) açısıdır. Bu değer üst ve alt yüzey için aşağıdaki gibi olacak şekilde tasarlanmıştır. Modern yolcu 
uçakları için ana taşıyıcı görevi gören kanatların kökten uca doğru bir sivrilme oranı olduğu gibi, kıvrık kanat ucu için de sivrilme oranları $\left(\lambda_{1}, \lambda_{2}\right)$ bu parametre göz önünde bulundurulmuştur. $\mathrm{Bu}$ parametre için tasarım yapılırken aşağıdaki değerler referans alınmıştır [10].

$$
\begin{aligned}
& \mathrm{h}_{2}=0,4 \mathrm{xh}_{1} \\
& 0^{\circ}<\emptyset_{1}<50 \\
& 90^{\circ}<\emptyset_{2}<180 \\
& 0,28<\lambda_{1}<0,33 \\
& 0,33<\lambda_{2}<0,4
\end{aligned}
$$

Kıvrık kanat ucunun alt ve üst yüzeyleri ayrıca ok açısına sahiptirler. Ok açısı değeri en fazla $65^{\circ}$ olacak şekilde tasarlanmıştır. Yarıçapın yüksekliğe oranı belirlenirken daha önceden yapılan bir çalışmada belirlenen formülden yararlanılmıştır [11].

$$
\mathrm{R} / \mathrm{h}=\mathrm{K}_{\mathrm{R}} \cos \left(\varnothing / 2+\prod / 4\right) / \cos \varnothing 4
$$

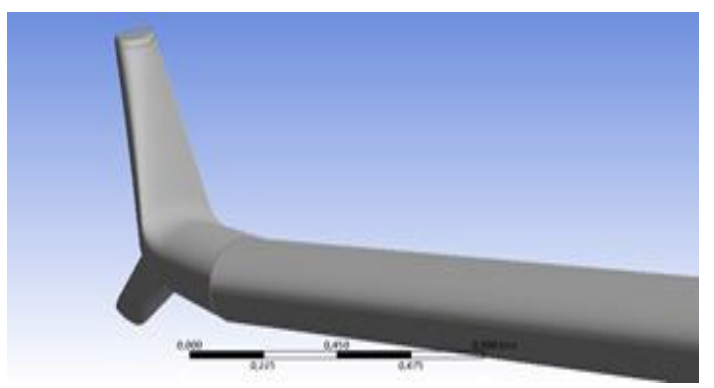

Şekil 4. $\mathrm{C}_{2}$ konfigürasyonu kıvrık kanat ucu görünümü

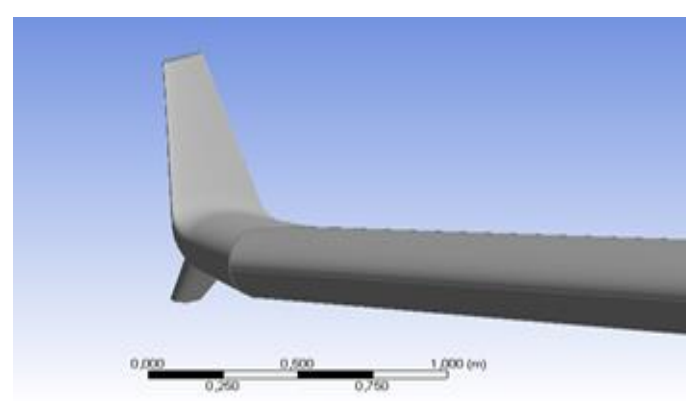

Şekil 5. $\mathrm{C}_{3}$ konfigürasyonu kıvrık kanat ucu görünümü

Dolayısıyla kıvrık kanat ucu tasarımlarının kök kısımları $C_{1}$ konfigürasyonun tip kısmına eş değer olacağından; değişkenlik gösteren ve kullanılan tüm değerlere Tablo 2'de yer verilmiştir. Değişkenlik gösteren değerler kıvrık kanat ucu maksimum tip

\begin{tabular}{|c|c|c|}
\hline $\begin{array}{l}\text { Konfigürasyon } \\
\text { İsmi } \\
\text { Parametre İsmi }\end{array}$ & $\mathrm{C}_{2}$ & $\mathrm{C}_{3}$ \\
\hline $\mathrm{h}_{1}$ & 0,76 metre & 0,76 metre \\
\hline $\mathrm{h}_{2}$ & 0,30 metre & 0,30 metre \\
\hline$\Lambda_{1}$ & $\cong 45^{\circ}$ & $\cong 45^{\circ}$ \\
\hline$\Lambda_{2}$ & $\cong 45^{\circ}$ & $\cong 45^{\circ}$ \\
\hline$\Theta_{\mathrm{T}}$ & $0^{\circ}$ & $0^{\circ}$ \\
\hline $\mathrm{C}_{\mathrm{T} 1}$ & $\begin{array}{l}0,8(0,73) \\
\text { metre }\end{array}$ & $\begin{array}{c}0,8(0,81) \\
\text { metre }\end{array}$ \\
\hline $\mathrm{C}_{\mathrm{T} 2}$ & 0,86 & 0,86 metre \\
\hline $\mathrm{C}_{\mathrm{R} 1}$ & 2,45 metre & 2,45 metre \\
\hline $\mathrm{C}_{\mathrm{R} 2}$ & 1,92 metre & 1,92 metre \\
\hline$i_{1}$ & $90^{\circ}$ & $90^{\circ}$ \\
\hline $\mathrm{i}_{2}$ & $90^{\circ}$ & $90^{\circ}$ \\
\hline$\lambda_{1}$ & 0,32 & 0,32 \\
\hline$\lambda_{2}$ & 0,44 & 0,44 \\
\hline 1 & 0,45 & 0,45 \\
\hline $\mathrm{R}$ & 0,168 metre & 0,168 metre \\
\hline $\begin{array}{l}\text { Üst Kıvrık Kanat } \\
\text { Uç Kalınlığı }\end{array}$ & 0,086 metre & 0,022 metre \\
\hline $\begin{array}{l}\text { Alt Kıvrık Kanat } \\
\text { Uç Kalınlığı }\end{array}$ & 0,1 metre & 0,035 metre \\
\hline
\end{tabular}
kalınlıkları ile veter $\left(\mathrm{C}_{\mathrm{T} 1}\right)$ uzunluklarıdır. Elde edilen kıvrık kanat ucu görselleri Şekil 4 ve Şekil 5'teki gibidir.
Tablo 2. $\mathrm{C}_{2}$ ve $\mathrm{C}_{3}$ konfigürasyonlarının tasarımında kullanılan parametreler

SolidWorks programı ile tasarlanan kanat çizimi parasolid dosyası olarak kaydedilerek Fluent Programında tanımlanabilecek bir dosya haline getirilmiştir. Fluent programında ă̆ yapısı oluşturulmadan önce hesap bölgesinin belirlenmesi gerekmektedir ve bu nedenle ilk olarak Workbench kısmında Şekil 6'dakiler gibi hesap bölgeleri oluşturulmuştur. Hesap bölgesi oluşturulurken 
kullanılan bilgisayarın özellikleri de belirleyici olmuştur. Çünkü çok büyük bir hesap bölgesi oluşturulduğu takdirde hücre sayısı çok olacak dolayısıyla çözüm süresi çok uzun olacaktır. Hesap
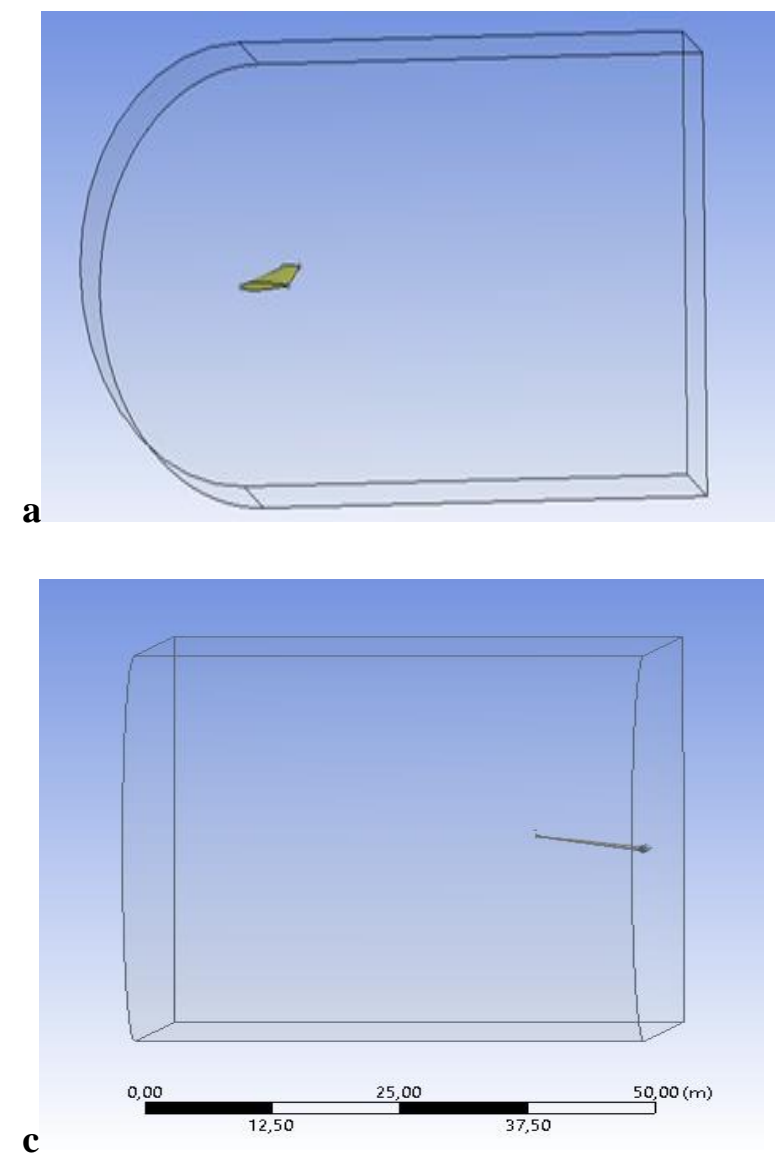

bölgesinin küçük olması durumunda ise akış etkilenecek ve analiz sonuçlarında değişikliklere neden olacaktır.

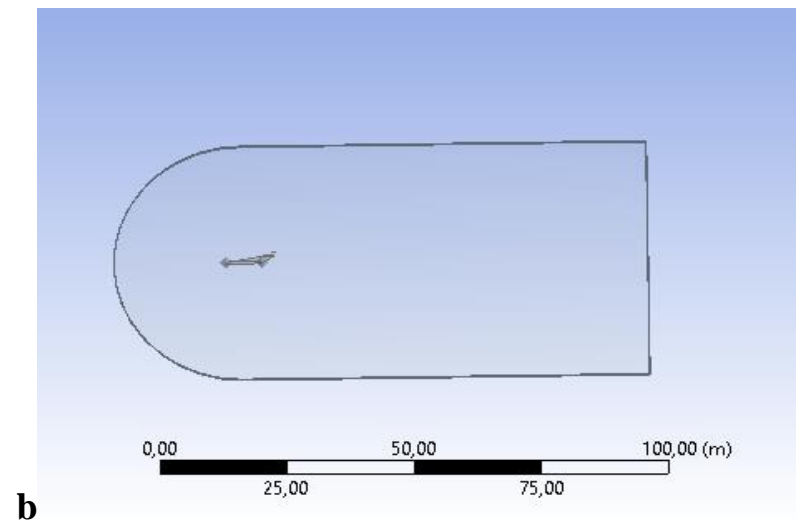

Şekil 6. Analizler için oluşturulan hesap bölgelerinin farklı bakış açılardan görünümleri (boyutları)

Hesaplamalı akışkanlar dinamiği çözümünde ilk adım olarak hesap bölgesindeki hücrelerin tanımlanması gerekmektedir. Hücrelerin şekli ve hücreler arası geçiş ne kadar düzgün tanımlanabilirse çözümde bulunan sonuçlar $\mathrm{o}$ kadar gerçeğe yakınlık göstermektedir. Hücrelerin tanımlanabilmesi için Şekil 7'den anlaşılabildiği gibi ağ yapılarının oluşturulması gerekmektedir. A $\breve{g}$ yapıları yapılandırılmış ve yapılandırılmamış olmak üzere iki türden oluşmaktadır. Tasarımda olduğu gibi 3 boyutlu şekiller için yapılandırılmış ağ kullanılarak oluşturulan bir hücre altı yüzden oluşmaktadır. Bir de bu iki ağ yapısının birlikte kullanıldığı melez ağ yapısı vardır. Bu çalışmada melez ağ yapısı Şekil 8'deki gibi kullanılmıştır. Kanat üzerinde yapılandırılmış ağ yapısı, diğer bölgelerde ise yapılandırılmamış ağ yapısı kullanılmıştır.

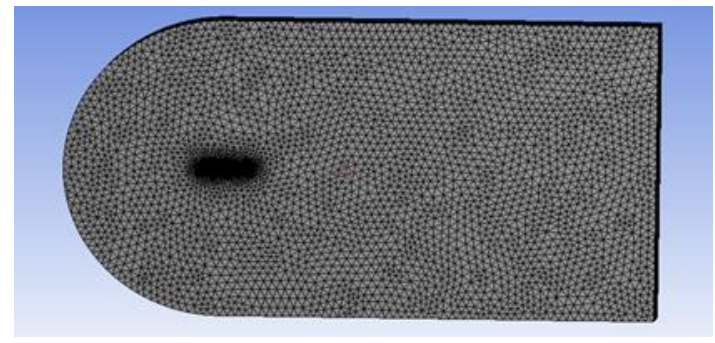

Şekil 7. Ağ yapıs1

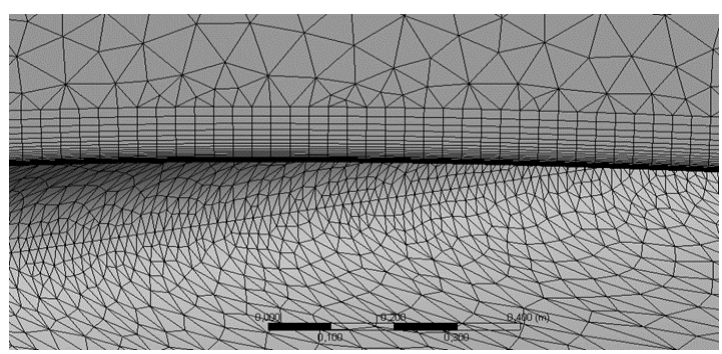

Şekil 8. Yapılandırılmış ve yapılandırılmamış ağ görünümü 
Ağ yapısı tanımlandıktan sonra uçağın on bin metre olarak düşünülen uçuş irtifasındaki ortam şartları belirlenerek programa girilmiştir. Buna göre akışkanın hava olması nedeniyle bu irtifadaki havanın sıcaklık, yoğunluk gibi özellikleri referans alınarak sınır değerler belirlenmiş ve gerçek uçuşla aynı ortam oluşturulmaya çalışılmıştır. Havanın o irtifadaki özellikleri Tablo 3'teki gibidir [12].

Tablo 3. 10000 metre irtifada havanın yoğunluk, sıcaklık ve basınç değerleri

\begin{tabular}{ll}
\hline İntensif Özellik & İrtifadaki Değerler \\
\hline$\rho$ (yoğunluk) & $0,4135 \mathrm{~kg} / \mathrm{m}^{3}$ \\
$\mathrm{~T}$ (sıcaklık) & $223,26 \mathrm{~K}$ \\
$\mathrm{P}$ (basınç) & $26500 \mathrm{~N} / \mathrm{m}^{2}$ \\
\hline
\end{tabular}

Çözümde belirleyici olan diğer önemli bir kıstas ise analizin hangi model ile yapılacağına karar verilmesidir. Model kararının verilebilmesi için akışın türbülanslı mı yoksa düz akış mı olduğunun bilinmesi gerekmektedir. Akışın, düz akışlı mı yoksa türbülanslı mı olup olmadığına Reynolds sayısına bakılarak karar verilebilmektedir [13]. Bunun için akışın Reynolds sayısı hesaplanmıştır ve çıkan sonuca göre türbülanslı bir akış olduğuna karar verilmiştir [14]. Reynolds sayıs1, bir akışkanın atalet kuvvetlerinin viskozite kuvvetlerine olan oranı olarak tanımlanmaktadır. Hava hızı olarak $210 \mathrm{~m} / \mathrm{s}$ kabul edilmiştir.

$$
R e=\frac{\vartheta L \rho}{\mu}
$$

Formülü yukarıdaki gibi tanımlanmaktadır. Buna göre yapılmış olan bu çalışma için:

$$
R e=\frac{210 \times 7 \times 0,4135}{1,469 \times 10^{-5}}=413 \times 10^{5}
$$

Dış akışlar için $\operatorname{Re}>5 \times 10^{5}$ olduğu durumlarda akış türbülanslıdır. Analizde ise $\mathrm{Re}=413 \times 10^{5}$ olmasından dolayı türbülanslı bir akış söz konusudur [15]. Çözümde kullanılacak model olarak, türbülanslı bir akış için uygunluğu nedeniyle k- $\omega$ SST (Shear-Stress Transport) türbülans modeli tercih edilmiştir [16]. Bu model Menter tarafından geliştirilmiştir. Özellikle duvar üzerindeki (bu çalışmada kanat ismi olarak tanıtılan) çözümlemeleri ve farfield (hesap bölgesi) alanındaki çözümlemeleri en iyi şekilde yapabilen türbülans modelidir $[17,18]$.

\begin{tabular}{|c|c|c|c|}
\hline $\begin{array}{c}\text { Konfigürasyon } \\
\text { İsimleri } \\
\text { Mesh Sayısı }\end{array}$ & $\begin{array}{c}\mathbf{C}_{1} \\
\mathrm{C}_{\mathrm{L}}-\mathrm{C}_{\mathrm{D}}\end{array}$ & $\begin{array}{c}\mathbf{C}_{2} \\
\mathrm{C}_{\mathrm{L}}-\mathrm{C}_{\mathrm{D}}\end{array}$ & $\begin{array}{c}\mathrm{C}_{3} \\
\mathrm{C}_{\mathrm{L}}-\mathrm{C}_{\mathrm{D}}\end{array}$ \\
\hline 2600000 & $\begin{array}{l}0,007453 \\
0,008161\end{array}$ & $\begin{array}{l}0,008318 \\
0,008510\end{array}$ & $\begin{array}{l}0,008586 \\
0,008345\end{array}$ \\
\hline 3800000 & $\begin{array}{l}0,007420 \\
0,008188\end{array}$ & $\begin{array}{l}0,008224 \\
0,008390\end{array}$ & $\begin{array}{l}0,008691 \\
0,008233\end{array}$ \\
\hline 4900000 & $\begin{array}{l}0,007374 \\
0,008143\end{array}$ & $\begin{array}{l}0,008347 \\
0,008329\end{array}$ & $\begin{array}{l}0,008679 \\
0,008297\end{array}$ \\
\hline
\end{tabular}

Tablo 4. A ̆̆ yapısı doğrulaması

A $\breve{g}$ sayısından bağımsızlığın sağlanabilmesi amaciyla çeşitli sayılarda ağlar oluşturulmuş. Farklı a ̆ sayılarına göre yapılan analizler sonucunda elde edilen $C_{L}$ ve $C_{D}$ katsayı değerlerine Tablo 4'te yer verilmiştir. Buna göre her bir konfigürasyon için $C_{L}$ ve $C_{D}$ değerlerindeki değişimin en az olduğu ve yine işlem zamanından kazanılabilmesi amacıyla en az sayıdaki mesh değerleri tercih edilmeye çalışılmıştır. Analiz sonuçlarının net sonuçlara dönüşebilmeleri için uygun iterasyon sayısına, aynı ağ sayıları ile farklı iterasyonda yapılan analizler sonucunda karar verilmiş ve $C_{L}$ ile $C_{D}$ değerlerindeki değişimler 1/10000 'lere düştüğünde 1000 iterasyonun yeterli olduğu düşünülmüştür. Bundan sonraki her analiz için Tablo 5'te yer alan ağ değerleri kullanılarak oluşturulan her bir konfigürasyon için 1000 iterasyon yapılması sağlanarak farklı hücum açılarında sonuçlar elde edilmiştir.

Tablo 5. Analizlerin yapıldığı ağ sayısı değerleri

\begin{tabular}{ccc}
\hline Konfigürasyon & Mesh Sayısı & $\begin{array}{c}\text { İterasyon } \\
\text { Sayısı }\end{array}$ \\
\hline $\mathrm{C}_{1}$ & 2680873 & 1000 \\
$\mathrm{C}_{2}$ & 4917464 & 1000 \\
$\mathrm{C}_{3}$ & 3883581 & 1000 \\
\hline
\end{tabular}




\section{Bulgular ve Tartışmalar}

Boyutsuz duvar mesafesi anlamına gelen $y+$ değeri elde edilen analiz sonuçlarının doğruluğu için önem arz etmektedir. Tablo 6' da sayısal analize başlamadan önce istenilen ve elde edilen $\mathrm{y}^{+}$ değerleri görülmektedir.
Tablo 6. $Y+$ değerleri

\begin{tabular}{ccc}
\hline Konfigürasyon & İstenilen Değer & $\begin{array}{c}\text { Elde Edilen } \\
\text { Değer }\end{array}$ \\
\hline $\mathrm{C}_{1}$ & 1 & 0,68 \\
$\mathrm{C}_{2}$ & 1 & 5,99 \\
$\mathrm{C}_{3}$ & 1 & 56,11 \\
\hline
\end{tabular}

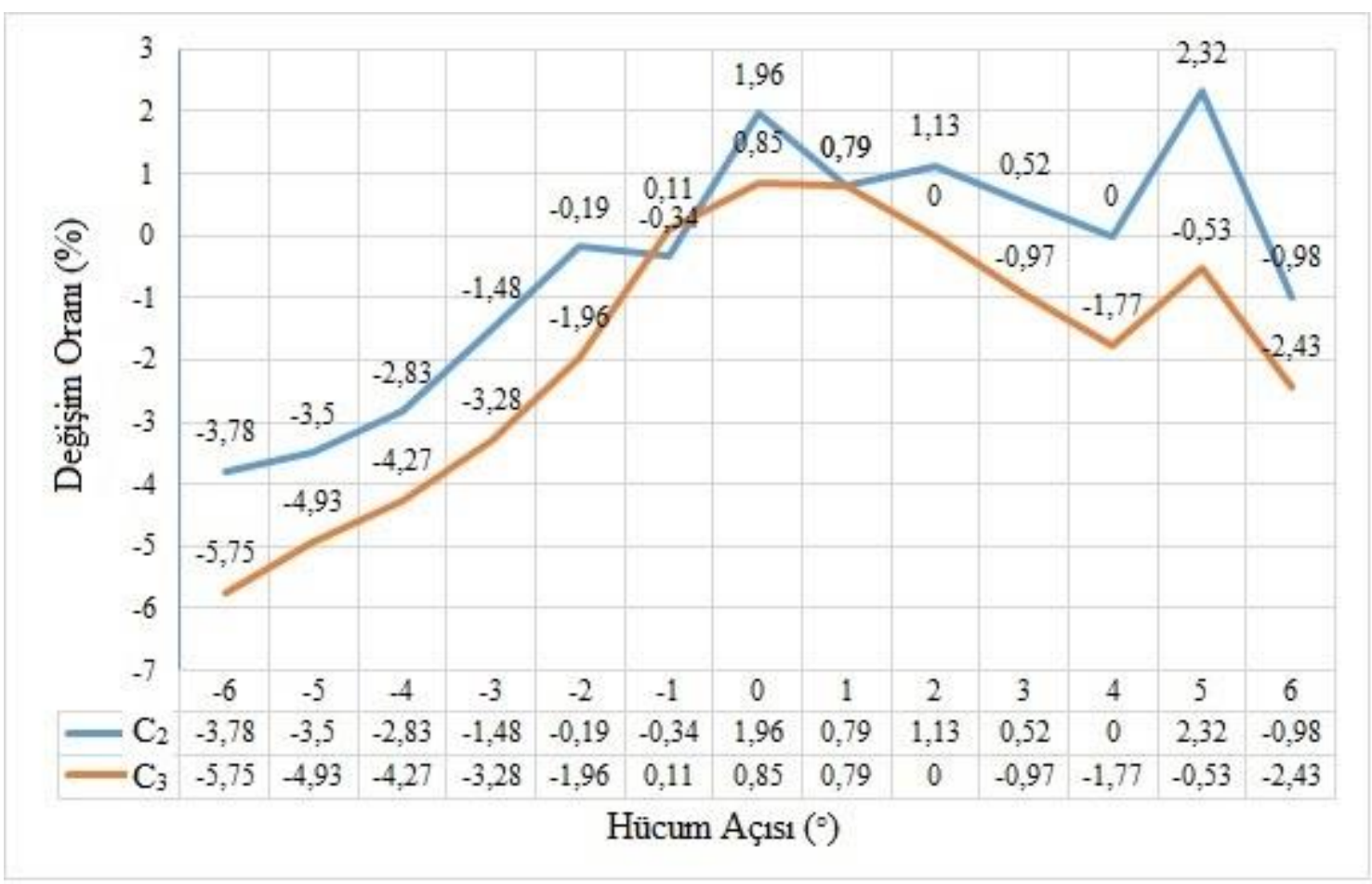

Şekil 9. Farklı hücum açılarında $\mathrm{C}_{1}$ konfigürasyonuna göre $\% \mathrm{C}_{\mathrm{D}}$ değişim miktarları

$\mathrm{C}_{2}$ ve $\mathrm{C}_{3}$ konfigürasyonlarının farklı hücum açılarında meydana gelen sürükleme katsayılarındaki değişimler $\mathrm{C}_{1}$ konfigürasyonuna göre yüzde olarak Şekil 9'da yer almaktadır. Özellikle negatif hücum açılarında \% 5,75' lere kadar azalma meydana geldiği görülebilmektedir. Buna rağmen bazı hücum açılarında sürükleme katsayılarında artışlar da meydana gelmiştir.
$\mathrm{C}_{2}$ ve $\mathrm{C}_{3}$ konfigürasyonlarının farklı hücum açılarındaki taşıma katsayısı sonuçları, $\mathrm{C}_{1}$ konfigürasyonu sonuçlarına göre yüzde değişim olarak karşılaştırıldığında Şekil 10'daki grafik elde edilmiştir. $\mathrm{C}_{3}$ konfigürasyonu için sıfır derece hücum açısında taşıma katsayısı değerinde \% 16,64' lük bir artış meydana gelirken eksi bir derece hücum açısında \% 2,51' lik bir azalış meydana gelmiştir. 


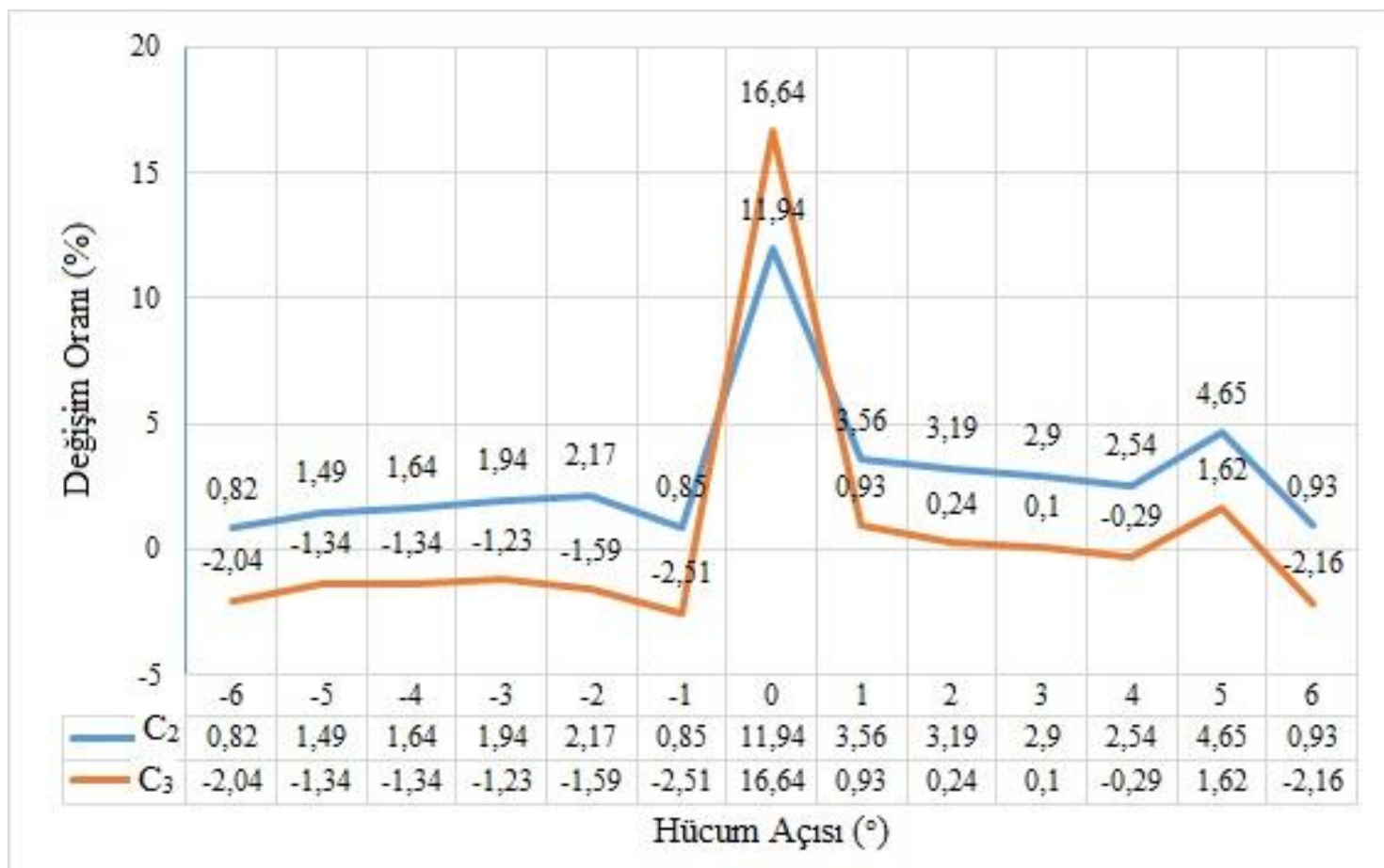

Şekil 10. Farklı hücum açılarında $C_{1}$ konfigürasyonuna göre $\% C_{L}$ değişim miktarları

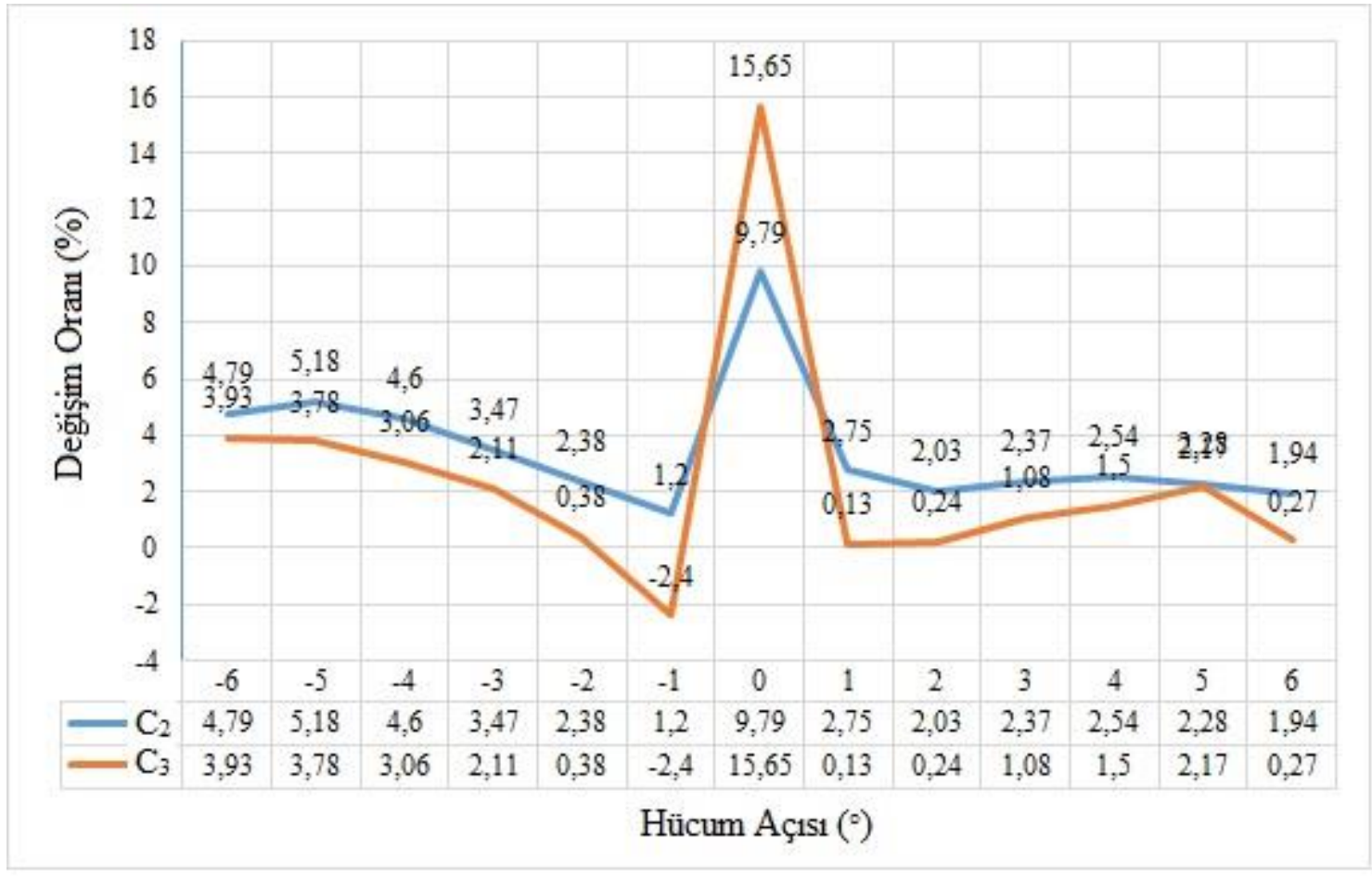

Şekil 11. Farklı hücum açılarında $C_{1}$ konfigürasyonuna göre $C_{L} / C_{D}$ oranındaki \% değişim miktarları

Farklı hücum açılarında $\mathrm{C}_{1}$ konfigürasyonu $\mathrm{C}_{\mathrm{L}} / \mathrm{C}_{\mathrm{D}}$ oranındaki değişimin $\mathrm{C}_{2}$ ve $\mathrm{C}_{3}$ konfigürasyonlarının $\quad \mathrm{C}_{\mathrm{L}} / \mathrm{C}_{\mathrm{D}} \quad$ oranlarındaki değişimlere göre yüzde olarak hesaplanmış halleri Şekil 11'de yer almaktadır. $C_{3}$ konfigürasyonunun eksi bir derecedeki taşıma katsayısının sürükleme katsayısına olan oranı hariç diğer bütün hücum açılarında arttığı gözlemlenmiştir. Bu durum kanat finesinin yani veriminin artmas1 olarak açıklanabilmektedir. 


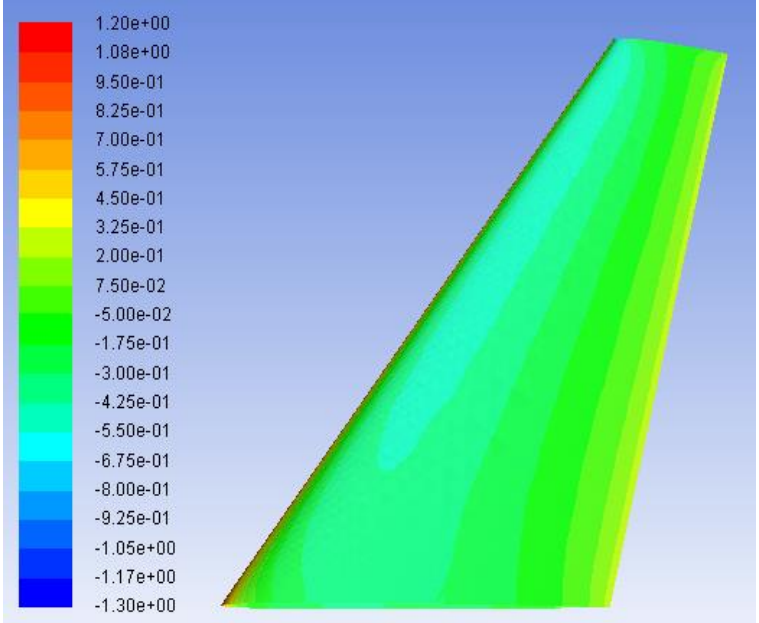

Şekil 12. $C_{1}$ konfigürasyonu üzerindeki basınç katsay1s1

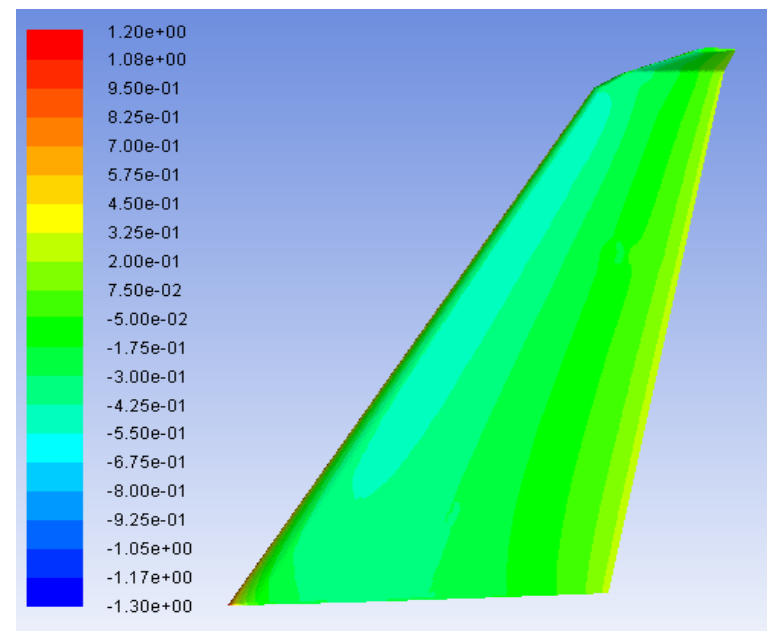

Şekil 13. $\mathrm{C}_{2}$ konfigürasyonu üzerindeki basınç katsay1s1

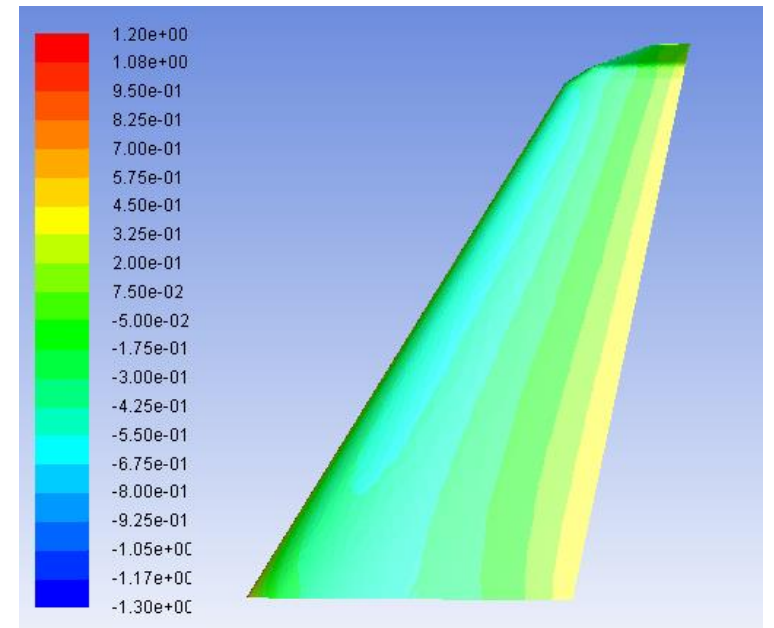

Şekil 14. $C_{3}$ konfigürasyonu üzerindeki basınç katsayı1 1

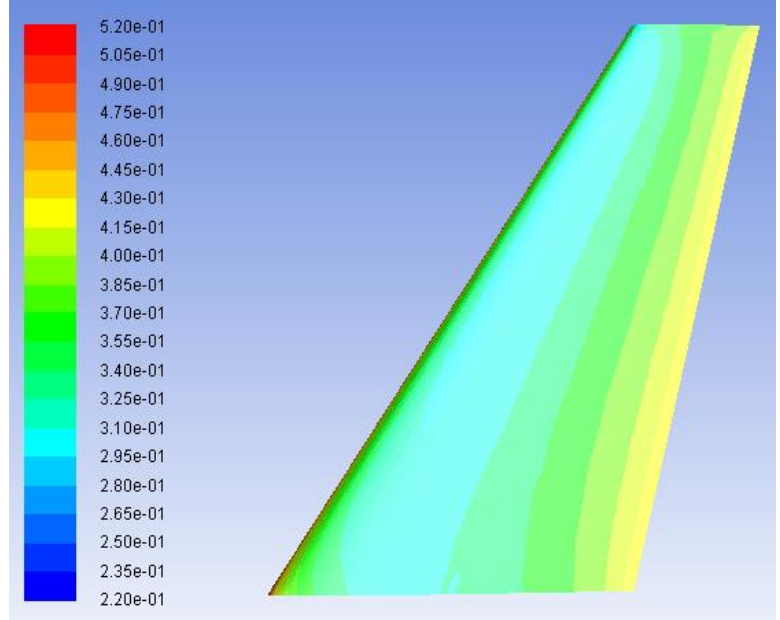

Şekil 15. $\mathrm{C}_{1}$ konfigürasyonu üzerindeki yoğunluk gösterimi

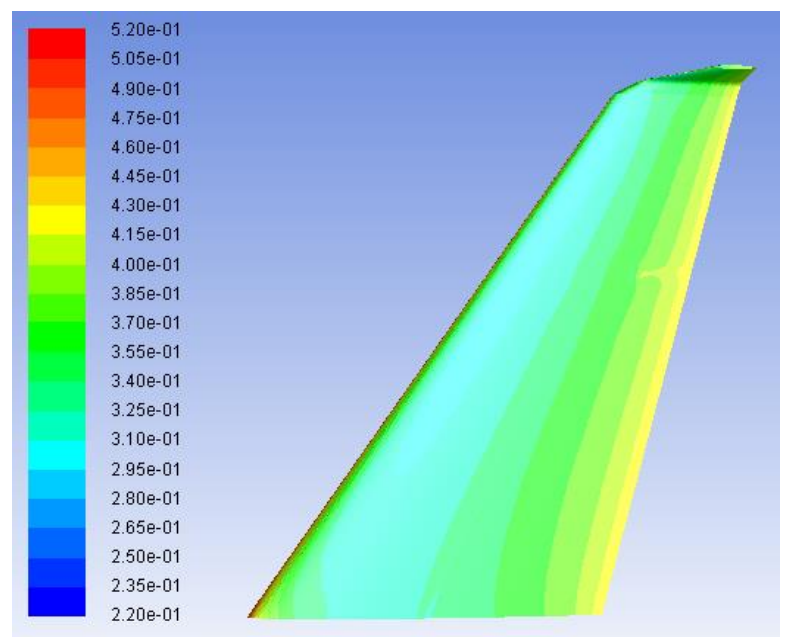

Şekil 16. $\mathrm{C}_{2}$ konfigürasyonu üzerindeki yoğunluk gösterimi

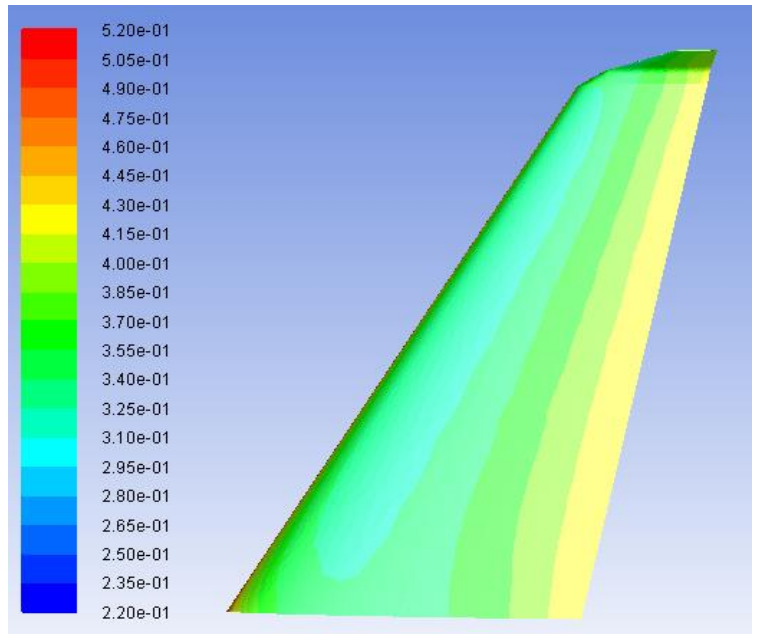

Şekil 17. $\mathrm{C}_{3}$ konfigürasyonu üzerindeki yoğunluk gösterimi 


\section{Sonuçlar}

$\mathrm{Bu}$ çalışmada $\mathrm{C}_{1}, \mathrm{C}_{2}$ ve $\mathrm{C}_{3}$ konfigürasyonları özellikle de $\mathrm{C}_{3}$ konfigürasyonunun farklı hücum açılarındaki sonuçları incelendiğinde sürükleme katsayısında azalma meydana geldiği görülmüştür. Sürüklemede azalma görülebildiği gibi taşıma katsayısında da artış gözlemlenmiştir. NACA 0012 gibi simetrik bir profile sahip kanatlar için sıfır derece hücum açısında taşıma oluşmaması gerekirken yapılmış olan bu çalışmada bir miktar taşıma meydana gelmiştir. $\mathrm{Bu}$ durum kısaca tasarlanan kanadın sahip olduğu dihedral ve ok açısı ile açıklanabilmektedir. Kanat yapıları üzerlerindeki bazı akışkan değişkenleri görsel olarak sunulmuştur. Kanat verimi yani kanat üzerinde meydana gelen taşıma katsayısının sürükleme katsayısına oranı incelendiğinde \% 15,65' lere kadar artış gözlemlenmiştir. Şekil 12, Şekil 13 ve Şekil 14 incelendiğinde kanat hücum kenarlarında havayla ilk karşılaşan bölge olması nedeniyle basınç katsayılarında ve Şekil 15, Şekil 16 ve Şekil 17 incelendiğinde benzer şekilde basınç katsayısı ile paralel olarak kanat hücum kenarlarında yoğunluk artışı gözlenmiştir.

\section{Simgeler}

$\begin{array}{lll}\mathrm{C}_{\mathrm{D}} & : & \text { Sürükleme katsayısı } \\ \mathrm{C}_{\mathrm{L}} & : & \text { Taşıma katsayısı } \\ \mathrm{C}_{\mathrm{r}} & : & \text { Kanat kök veter uzunluğu } \\ \mathrm{C}_{\mathrm{t}} & : & \text { Kanat uç veter uzunluğu } \\ \varepsilon & : & \text { Epsilon } \\ \mathrm{HAD} & : & \text { Hesaplamalı akışkanlar dinamiği } \\ \mathrm{h}_{1} & : & \text { Üst kıvrık kanat yüksekliği } \\ \mathrm{h}_{2} & : & \text { Alt kıvrık kanat yüksekliği } \\ \mathrm{K}_{\mathrm{R}} & : & \text { Eğrilik kriteri } \\ l_{W} & : & \text { Ağrllı merkezi ile taşıma kuvveti } \\ & & \text { arası uzaklık } \\ \mathrm{R} & : & \text { Kıvrık kanat geçiş bölgesi eğrilik } \\ & & \text { yarıçapı } \\ \mathrm{Re} & : & \text { Reynolds sayısı } \\ \mathrm{T}_{0} & : & \text { Kelvin cinsinden referans sıcaklık } \\ \mathrm{U} & : & \text { Hız } \\ \alpha & : & \text { Hücum açısı } \\ \mu & : & \text { Dinamik viskozite } \\ \mu_{0} & : & \text { Referans sıcaklığında referans viskozite } \\ k & : & \text { Türbülans kinetik enerji } \\ r & : & \text { Yayılım } \\ \kappa & : & \text { Von Karman sabiti } \\ & & \end{array}$

$\begin{array}{lll}\mu_{\mathrm{t}} & : & \text { Türbülans viskozite } \\ \rho & : & \text { Yoğunluk } \\ \sigma_{\omega} & : & k \text { - } \omega \text { türbülans model sabiti } \\ \omega & : & \text { Açısal hız } \\ Y_{k}-Y_{\omega} & : & \text { Enerji yitimi } \\ G_{k} & : & \text { Türbülans kinetik enerji üretimi } \\ \emptyset_{1}-\emptyset_{2} & : & \text { Cant açıları } \\ \Lambda_{1}-\Lambda_{2} & : & \text { Ok açıları (sweep angle) } \\ \Theta_{\mathrm{T}} & : & \text { Burulma açıs1 (twist angle ) } \\ \mathrm{C}_{\mathrm{T} 1}-\mathrm{C}_{\mathrm{T} 2} & : \text { Kivrık kanat uç kısımları uzunluğu } \\ \mathrm{C}_{\mathrm{R} 1}-\mathrm{C}_{\mathrm{R} 2} & : \text { Kivrık kanat kök kısımları uzunluğu } \\ \mathrm{i}_{1}-\mathrm{i}_{2} & : \text { Kanat geliş açısı (incidence-toe angle) } \\ \lambda_{1}-\lambda_{2} & : \text { Sivrilme oranı (taper ratio) } \\ l & : \text { Kivrık kanat ucu açılığı (span) }\end{array}$

\section{Teşekkür}

Bu çalışmada kullanılan Fluent ve SolidWorks Programları ile iş istasyonları kullanım izinleri için yazarlar, Türk Hava Kurumu Üniversitesi İnsansız Hava Aracı Merkezi' ne (THKÜ İHAMER) teşekkür ederler.

\section{Kaynaklar}

[1] Tyler T. (2016). "International Air Transport Association Annual Review," 72nd Annual General Meeting, Dublin.

[2] Maughmer, D. M. (2001). The Design of Winglets for High-Performance Sailplanes, The American Institute of Aeronautics and Astronautics, 2406, 1-11.

[3] Maughmer, D. M., Swan, T. S., Willits, S. M. (2001). The Design and Testing of a Winglet Airfoil for Low-Speed Aircraft, The American Institute of Aeronautics and Astronautics, 2478, 1-10.

[4] Menter, F. R., Kuntz, M., Langtry, R. (2003). Ten Years of Industrial Experience with the SST Turbulence Model, Turbulence, Heat and Mass Transfer, 4, 1-8.

[5] Nicolosi, F., Marco, A. D., Vecchia, P. D. (2011). Flight Tests, Performance, and Flight Certification of a Twin-Engine Light Aircraft, Journal of Aircraft, 48 (1), 177-192. Curry, M (2008). Winglets. http://www.nasa.gov/centers/dryden/about/ Organizations/Technology/Facts/TF-2004- 
15-DFRC.html. Erişim tarihi Mayıs 18, 2016.

[7] Whitcomb, R. T. (1976). A Design Approach and Selected Wind-Tunnel Results at High Subsonic Speeds for WingTip Mounted Winglets, NASA Langley Research Center Hampton, Washington, 33.

[8] Elham, A., Tooren, M. J. L. V., 2014. Winglet multi-objective shape optimization. Aerospace Science and Technology, 37: 93109.

[9] Reddy, S. R., Sobieczky, H., Abdoli, A., Dulikravich, G. S., Multi-Winglets: MultiObjective Optimization of Aerodynamic Shape, 53rd AIAA Aerospace Sciences Meeting, AIAA.

[10] Gratzer, L.B. "Split blended winglet," US patent 0312 928, Dec. 13, 2012.

[11] L.B. Gratzer, "Blended winglet," US patent 5348 253, Sep. 20, 1994.

[12] Anderson, J.D. (1999). Aircraft Performance and Design, The McGraw-Hill Companies, United States of America, pp. 302.

[13] Snorri, G. (2014). General Aviation Aircraft Design: Applied Methods and Procedures. Butterworth-Heinemann is an imprint of Elsevier, USA.

[14] Bertin, J. J., Russell, M. C. (2014). Aerodynamics for Engineers Sixth Edition, Pearson Education Limited, London.

[15] Ansys CFX-Solver Theory Guide, 2009.

[16] Nichols, R. H., Turbulence Models and Their Application to Complex Flows. University of Alabama, Birmingham, Revision 14.1.

[17] Celik, I. B. (1999). Introductory Turbulence Modeling. Mechanical and Aerospace Engineering Department, West Virginia University.

[18] Ansys Fluent Theory Guide, 2013. 